\title{
Creativity and Mood Disorders: Both Deviances?
}

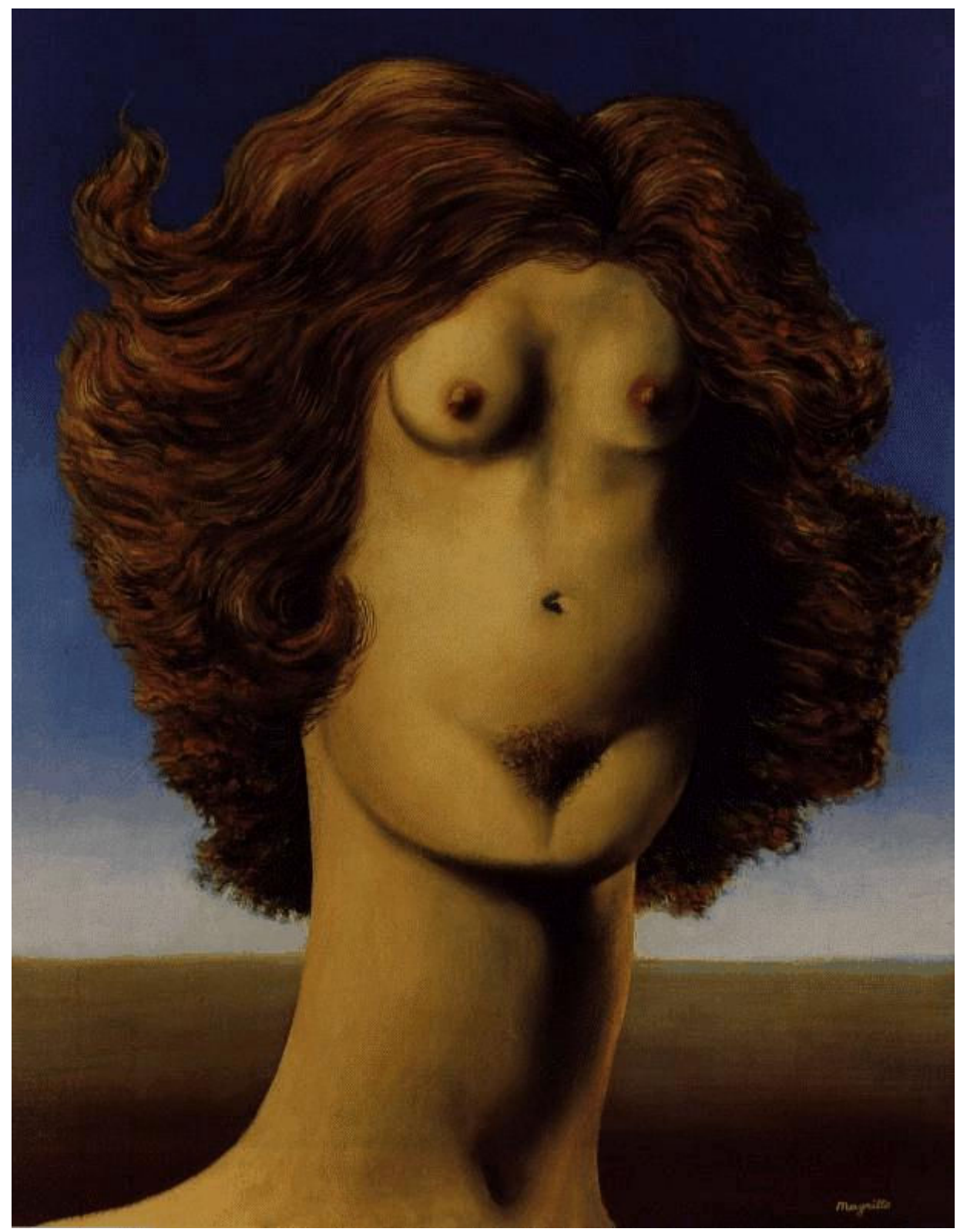

René Magritte, The Rape, 1934.

Please cite as:
LeBel, E. P. (2002). Creativity and mood disorders: Both deviances? Unpublished
manuscript, University of Waterloo. Retrieved from: https://osf.io/z49kg


Creative individuals have shaped our world in vital ways for as long as we have existed. Even less renowned creativity is a quality which is very helpful and highly valued. It is then a natural question to ask if creative individuals possess anything special or are predisposed in some way that would facilitate their creativity. In this paper, this question and others concerning creativity will be investigated: Does creativity lead to affective disorders? Are affective disorders a precursor needed or leading to creativity? Do mood disorders interfere with rather than promote creativity? Could there be a certain concept that is linked to both creativity and mood disorders? It is important to be aware of how creativity is measured. Mood disorders, as classified by the Diagnostic and Statistical Manual of Mental Disorders - IV (DSM-IV), such as major depression disorder, bipolar I, bipolar II, and cyclothymic disorder will be discussed. The first part of this paper will give a brief history of creativity and provide a psychoanalytic, behavioural, and biological perspective on creativity and mood disorders. The main body of the paper encompasses presenting evidence for two core statements: it would seem as though certain mood disorders facilitate creative states; and creativity puts an individual at risk for a mood disorder. Finally, a brief description of deviance and its relevance to creativity and mood disorders will be presented. A brief introduction of creativity is now presented.

Creativity and madness has been contemplated since the times of Plato and Aristotle. Plato describes creativity as poetic, prophetic, ritual, and erotic madness while Aristotle sees creativity as a rational system stemming from natural causes (Ludwig, 1992). Kris, Haynal, and Freud all propose a psychoanalytic theory of creativity. Kris (1952) states that creative work is the result of an individual regressing away from the ego source. An id regression, according to Kris, would result in a completely irrational process, whereas an ego regression gives rise to a loss of control but a subsequent sense of control. This process could facilitate an inventive, 
creative outlook on normal everyday processes, which could result in original work. Haynal (1976) noticed that quite a few prominent individuals were unable to produce creative work until after their caregiver's death (e.g. Freud, Voltaire, Camus, Sartre). He posits that the drive behind one's creativity can be attributed to the need to become independent and rely on one's own resources. Furthermore, Haynal states "creation is thus a defense against the anxiety of separation from the gratifying maternal protection, a defense against a 'lack' and attendant castration anxiety" (p. 144). In sum, he suggests that creative work is a re-creation of the lost object which allows for a better integration of one's inner world. Freud (1916/1964) suggests that creativity is an entirely unconscious process which is based on drives that people are unaware of; thus the conscious part of creativity seems to be completely ignored (Eisenman, 1997).

A behavioural perspective on creativity and mood disorders is related in some way to the psychoanalytic theory. A behavioural viewpoint, however, focuses on the adaptive function of creativity. If an individual draws on his creativity successfully in order to cope with a life stressor, then he learns this behaviour pattern and can re-utilize it in the future. This view contradicts the ideas of Eisenman(1997), Andreasen(1994), and Rothenberg (1990) who all suggest that depression interferes with creative work. This idea will be looked at in more detail when the first part of this paper's thesis is discussed. Nonetheless, following the idea of Kris, it would seem that creativity is a means to cope with an emotional life crisis. This creative behaviour is thus reinforced by its effectiveness in dealing with the life stressor. One must speculate, however, whether a pre-existing creative ability must be present in an individual in order for this strategy to be employed in the situation. For sake of argument, however, assuming an individual has the creativity ability, it is employed and becomes a reinforced behavioural 
tendency. The example of the French painter René Magritte from Gedo (1992) serves as a good example. Magritte's suicidal mother eventually drowned herself and Magritte was unable to integrate the incident within himself. He used his art as a means to relive the moment surrounding the tragic event. He would express his sense of isolation and his loss, through the portrayal of barren landscapes painted in somber colours. His eventual recognition by the French art world jolted him into a frenzied state, which produced eccentric, bizarre, and at times even vulgar paintings. Thus, through his artistic, creative abilities, he was successful at fighting his mental problems, avoiding a tragic outcome, death, which no one in the art world would have ever wanted. ${ }^{1}$ In sum, although these and the psychoanalytic viewpoints are untested theories, they nonetheless contribute to the ideas on creativity and mood disorders and stimulate future investigations on the subject.

We now turn to a biological perspective on creativity and mood disorders. Richards et al. (1988) found that relatives of manic-depressives or cyclothymes predicted the highest level of creativity. Thus, there might exist a "positive compensatory advantage" to genes linked to bipolar disorder (Kinney \& Matthysee, 1978). An approximate analogy to this is the asymptomatic heterozygous form of sickle-cell anemia being advantaged by resistance to malaria (Richards et al., 1988). Another biological perspective put forth was by Post (1996) who based his idea on Dennett's (1991) hypothesis of reducing the consciousness to complex neural networks in the brain. Post conceptualizes affective illnesses as the result of a sequence of hyperactive neural events (Post, 1996). He further suggests that the hyperactivity of neural networks can also be caused by creative efforts, especially verbal creativity (Post, 1996). Thus, the high emotionality of creative individuals, leading to neural network hyperactivity in the brain, may be an integral causal factor in creating mental disturbances (Post, 1996). Eisenman

\footnotetext{
${ }^{1}$ Please refer to the cover page and Appendix A for examples of René Magritte's creative masterpieces.
} 
(1997) witnessed an intellectually creative friend, who was a writer, acquiring symptoms of bipolar disorder (e.g. incoherent racy speech, shifting ideas) from one day to the next. Although it is only one case, it is nonetheless an indicator that creativity and unbalanced biochemical brain processes might well be linked. It has been suggested that changes in the body that causes harmful things may also produce positive things which might facilitate creativity (Eisenman, 1997). Hoppe (1988) speculates that certain brain functions which control emotions may also increase creativity. He further adds that some brain pathologies that lead to mood disorders might reduce social inhibitions which could allow an individual to be less worried about being eccentric, which could then enable them to be more creative. Miller (1988) speculates there might be a specific gene responsible for both manic pathology and creativity (Eisenman, 1997).

The first part of the main thesis will now be presented. Many studies have revealed that certain affective disorders promote creative behaviours. Particularly, it has been shown that the mild form of manic states of bipolar I, is the most effective in producing creativity in individuals. Eisenman (1997) proposes that a hypomanic state gives a person a surge of energy enabling them to think of many different things at the same time (Eisenman, 1997). The individual could then possibly make original combinations of these ideas and produce a creative piece of work. In fullblown mania, however, an individual may also be bombarded with many unusual ideas, but one cannot be productive because of the extreme debilitating nature of the manic state (Eisenman, 1997).

Richards and Kinney (1990) found that mood swings could enhance creativity not only in eminent individuals but also in everyday creativity (non-socially-recognized work). Consistent with Eisenman, they also found that a milder mood, not an extreme one (as in bipolar I), appears to be the most facilitative for creativity (Richards \& Kinney, 1990). They further propose that 
possible underlying causes for the increase in creativity in mild mood swings pertain to characteristics of cognition (e.g., rapid thinking), affect (e.g., euphoria), as well as motivational factors (e.g., energy) (Richards \& Kinney, 1990). Furthermore, Richards and Kinney (1990) notice that everyday creative individuals are relatively healthy as compared to eminent creative individuals which more often have major mood disorders. They accounted for this difference by saying that in major mood disorders, the facilitation pertains more to a motivational factor than to the creative process; this might increase chance of eminency when creative talent is preexisting (Richards \& Kinney, 1989).

On a different note, contrary to stereotypical beliefs, depression seems to interfere rather than facilitate the creative process. Depression intuitively does not seem conducive to any productive behaviour, let alone creative behaviours. However, different scientists have different viewpoints on this topic. Eisenman (1997) proposes that creativity often involves high-level thinking which is severely impaired in major depression. It would seem that creativity involves superior thinking, not a distorted thinking which often arises in major depressive disorder and bipolar disorder (Boden, 1990). In Eisenman's prisoner study, the most creative individuals were those with conduct disorders, not the psychotic individuals (Eisenman, 1992).

Rothenberg (1990) reinforces that mental disturbances such as major depression do in fact interfere with the creative process. He states that no mental disturbance is uniformly impacting an individual at any one time (Rothenberg, 1990). Thus, he proposes that the creative process is very dynamic, a result of the interplay of the mental disturbance and the person's emotional state within his environment at any point in time. But during serious bouts with depression, creativity is severely impeded, and an individual's life can become at risk. In history, several writers suffering from serious depression have also eventually experienced writer's block 
and have committed suicide (Rothenberg, 1990). Thus, Rothenberg concludes that all types of mental disturbances entail extra anxiety that tends to disrupt the creative process (Rothenberg, 1990).

However, some persist to think that depression motivates creative processes. Schildkraut, Hirshfeld, and Murphy (1994), suggests that for some artists of the New York Abstract Expressionist School, severe depression may have provided an advantage of "bringing the artist into direct and lonely confrontation with the ultimate existential question, whether to live or to die" (p. 477). The sample size of the group observed was very small and so reliability of the data is in question. A more sensible viewpoint comes from Hershman and Lieb (1988) who propose that creativity can be fostered by depression, but only when the depressive state is of a bipolar disorder type. Thus, a manic depressive individual fuels his many bizarre ideas during his high state and then his low states enable him to critically sort out his ideas and produce a sensible piece of creative work. This data is not supported by scientific evidence, however, and is based mainly on case studies.

Finally, both bipolar disorder and depression could indeed lead to an increase in creativity. As mentioned in the biological perspective paragraph, mood disorders in general can sometimes decrease social inhibitions which can lead to an increase in atypical behaviours sometimes needed for creativity. This reduced social inhibition no longer limits an individual in his actions and could therefore maximize his chances in breaking new grounds.

The second part of the main thesis will now be presented. The reverse relation between creativity and mood disorders has also been supported. That is, creativity can put an individual at risk for certain mood disorders. Ludwig (1992) investigated creative accomplishments across various professions and looked for relations to different psychopathologies. Creative 
achievement was measured using the Creative Achievement Scale (CAS) and psychopathologies categorized according to Glossary descriptions in the Ninth Revision of the International Classification of Disease. Results showed that the "creative arts" group was at a much greater risk for depression and mania and underwent psychotherapy more often (Ludwig, 1992). These differences between professions suggest that the professional creativity employed by the individual may direct an individual towards psychopathologies such as depression or mania (Ludwig, 1992). For example, poets may be influenced by cultural expectations that they are supposed to struggle with themselves in order to produce creative work, while public official employers must remain non-affective in their daily work (Ludwig, 1992). The study did not provide high external validity due to the limitations in the biographical method employed to gather the data.

Ludwig (1994) completed another study on women writers specifically and psychopathologies. Ludwig obtained results consistent with the study described above. Women writers were considerably more debilitated on all the mental disorders than a matched control group (Ludwig, 1994). Specifically, depression occurred in 56\% of the writers, twice as common as the next mental disorder (Ludwig, 1994). The writers' creativity seemed to propel them into the inevitable erratic aura encompassing their profession.

According to Ludwig's two studies, it would seem as though certain professions incline individuals to develop depression or bipolar disorder. What kind of mechanism or underlying variables could possibly account for this trend? Post (1996) suggests different hypotheses in attempt to account for poets exhibiting less major depression than prose- and playwrights. $\mathrm{He}$ suggests that poets are generally better off than their prose- and playwright counterparts since they do not have to get as involved in their writing. In other words, a prose- or playwright must 
envision all possibly conflicting roles in a play/story which according to Post, entails "far more intensive emotional imagination and empathy" (p. 554). In contrast, a poet can be creative and only partially touch upon certain emotionally draining situations. Post's findings were consistent with Ludwig's (1992) study. For example, writers of fiction demonstrated more depression than poets who showed more mania (Ludwig, 1992). Furthermore, architects/designers and scientists (who also depend on creativity in their daily lives) showed the least amount of depression or mania amongst the creative group. Post's explanation to account for this would parallel the explanation used for the poets and expository writers: architects and scientists do not have to emotionally submerge themselves in completing their works, thus do not experience affective disorders as often.

The biological perspective suggested by Post (1996) is supporting evidence that creativity predisposes an individual to developing a mood disorder. As mentioned earlier, Post suggests that the high emotional arousal needed for creative ground-breaking behaviour is associated with excessively high neural network activities which becomes an important variable in causing mood disorders (Post, 1996). Thus, it is rather clear from Post's model of creativity and neural network excitability, that creativity inevitably leads an individual to developing certain mood disorders.

Rothenberg (1990) states that "creative processes may turn into psychotic ones" (p. 164). He argues that the creative process entails paradoxical ideas and fusion of antagonizing objects into single entities (the janusian process)(Rothenberg, 1990). In everyday logical and scientific thinking, contradictions either are resolved or cancel each other out. Similar to Post's idea described above, the process in which contradictory ideas are fused together creates tension and anxiety, which could lead to an affective disorder. As Rothenberg states: "Imagine the feelings and thoughts involved in formulating, for the first time, the following ideas within the janusian 
process: time moves forward and backward simultaneously (Richard Feynman); the sun rises and at the same time does not rise (Ernest Hemingway); a body moves and is simultaneously stationary (Albert Einstein)" (p. 162). Thinking of ideas of this sort on a consistent basis entails a significant strain on the person and their mental health is inevitably at risk.

One counter argument worth adding is one made by Cropley (1990) concerning how creativity is actually needed for mental health. He suggests that creativity is connected with psychological characteristics such as openness, autonomy, playfulness, and flexibility (Cropley, 1990). These characteristics are integral to a mentally healthy person and highly valued qualities in our society. Burkhardt (1985), however, argues that today's modern world identifies itself with uniformity and sameness which fosters an unhealthy anti-creative "mass dogma". (Cropley, 1990). Cropley also posits that creativity is better developed naturally as opposed to "training" individuals formally in being divergent; small studies did support this hypothesis (Stranger, 1987; Scheliga, 1988). Nonetheless, there might be a pinch of truth in Cropley's view that creativity developed in every day activities can possibly improve mental health.

Thus, one can see that both sides of the debate are well supported. It would seem as though mood disorders do in fact lead to heightened creativity. At the same time, creativity can also inevitably lead to the development of certain mood disorders. Thus, as Rothenberg describes fittingly: "Mental suffering is considered both the generator and the price of creativity" (p. 158).

Before closing a relatively new concept of creativity and mood disorders proposed by Eisenman will be presented. He posits that people can understand the link between creativity and mental illness better if they use the concept of deviance. Deviance is sometimes misconceived as entailing only negative behaviours. But Eisenman suggests that to be creative is by definition to be deviant, where deviance simply implies away from the norm (Eisenman, 1997). Creative 
people are often involved in activities which are unconventional and disliked by other normative members of society. Thus, he sees that creativity and mental illness are encompassed by deviance, since deviance focuses on behaviours which stray from the norm, as a concept to be investigated. So it would seem that creativity and mood disorders could be interpreted as both being deviances in order to more fully understand their relation. He further states that deviance might also explain his findings that illicit drug use correlate positively with creativity (Eisenman, 1997). Martindale (1989) offers an alternative explanation suggesting that drug usage can be part of psychopathological processes which may be part of the same creative processes (Martindale, 1989). Thus, if Martindale is correct in his hypothesis, then the national War on Drugs policy may be hindering the creative processes of many potentially valuable individuals in our society. On a related note, Andreasen (1994) suggests that we must think about the future of disrupting creativity in light of improved individual pharmacological treatments for certain mental illnesses. Although there is minimal objective data on the topic, Andreasen suggests that most of the evidence at this time shows that treatment does not impede the creative processes of the individuals, but can actually at times improve their creativity (Andreasen, 1994).

In summary, a psychoanalytical perspective which focused on ego source regression has been presented. In the behavioural viewpoint, the adaptive function of mood swings and how one may learn to utilize their creativity to deal with life situations has been presented. Biologically, different proposed models put forth included Post's neural network hyperactivity model and Richards et al.'s genetic data showing that relatives of bipolar and cyclothymic individuals show the greatest creativity. The first part of this paper's thesis presented evidence that mood disorders facilitate creativity. Hypomanic states have been shown to heighten creativity in both eminent and everyday creativity. Evidence for depression is mixed; some evidence shows that it directly 
interferes with creativity while other evidence shows that depression facilitates creativity, especially in the low states of manic depression. Some think that both hypomanic and depression facilitate creativity in that they both reduce social inhibitions. The second part of this paper's thesis presented evidence that creativity can put individuals at risk for certain mood disorders. Ludwig's data suggests that creative professions especially playwrights and prose writers are at a significant risk to develop a mood disorder. Post's biological data represents good evidence that creativity is paralleled to mental disturbances. Rothenberg suggests that the paradoxical thinking involved in creative processes may lead to mood disorders. A counter argument is presented that creativity is actually essential for good mental health. In conclusion, it is evident that both sides of the debate are strongly supported. It would perhaps seem that a mood disorder leads to creativity but at the same time is the cost for the creativity. Nonetheless, much further research is needed on the subject, especially considering the fact that creativity and mood disorders represent critical but vital aspects of our society. 


\section{References}

Boden, M.A. (1990). The creative mind: Myths and mechanisms. New York: Basic Books.

Burkhardt, H. (1985). Equality mania Conformity mania. Tubingen, Germany: Hohenrain.

Cropley, A.J. (1990). Creativity and mental health in everyday life. Creativity Research Journal, 3, 167178.

Dennet, D.C. (1991). Consciousness Explained. London: Penguin.

Eisenman, R. (1992). Creativity in prisoners: Conduct disorders and psychotics. Creativity Research Journal, 5, 175-181.

Eisenman, R. (1997). Mental illness, deviance, and creativity. In M. Runco (Ed.), The Creativity Research Handbook. Cresskill, NJ: Hampton Press Inc.

Freud, S. (1964). Leonardo da Vinci and a memory of his childhood. New York: Norton. (Original work published 1916).

Gedo, John E.; Gedo, Mary M. (1992). Perspectives on Creativity. Norwood, NJ: Alex Publishing Corporation.

Haynal, André (1976). Depression and Creativity. New York, NY: International Universities Press Inc.

Hershman, D.J., \& Lieb, J. (1988). The key to genius: Manic-depression and the creative life. Buffalo, NY: Prometheus Books.

Hoppe, K.D. (1988). Hemispheric specialization and creativity. Psychiatric Clinics of North America, 11, 303-315.

Kinney, D.K., \& Matthysse, S. (1978). Genetic transmission of schizophrenia. Annual Review of Medicine, 29, 459-473.

Kris, E. (1952). Psychoanalytic explorations in art. New York: International Universities Press.

Ludwig, A.M. (1992). Creative achievement and psychopathology: comparison among professions. American Journal of Psychotherapy, 46, 330-353.

Ludwig, A.M. (1994). Mental illness and creative activity in female writers. American Journal of Psychiatry, 151, 1650-1656.

Martindale, C. (1989). Personality, situation, and creativity. In J.A. Glover, R.R. Ronning, \& C.R. Reynolds (Eds.), Handbook of creativity (pp. 211-232). New York: Plenum.

Miller, L. (1988). Ego autonomy, creativity, and cognitive style: A neuropsychodynamic approach. Psychiatric Clinics of North America, 11, 383-397.

Post, F. (1996). Verbal creativity, depression and alcoholism: an investigation of one hundred American and British writers. British Journal of Psychiatry, 168, 545-555.

Richards, R. \& Kinney, D. (1989). Creativity and manic-depressive illness (letter). Comprehensive Psychiatry, 30, 272-273.

Richards, R. \& Kinney, D. (1990). Mood swings and creativity. Creativity Research Journal, 3, 203-218.

Richards, R., Kinney, D., Lunde, I., Benet, M., \& Merzel, A.P.C. (1988). Creativity in manicdepressives, cyclothymes, their normal relatives, and control subjects. Journal of AbnormalPsychology, 97, 281-288.

Rothenberg A. (1990). Creativity and Madness: New Findings and Old Stereotypes. Baltimore: Johns Hopkins University Press.

Scheliga, J. (1988). Making music and the fostering of creativity. Unpublished master's thesis, University of Hamburg, Hamburg, Germany.

Schildkraut J.J., Hirshfeld A.J., Murphy J.M. (1994). Mind and mood in modern art, II: depressive disorders, spirituality, and early deaths in the Abstract Expressionist artists of the New York School. American Journal of Psychiatry, 151, 482-488.

Stranger, A. (1987). Legasthenia and divergent thinking. Unpublished master's thesis, University of Hamburg, Hamburg, Germany.

Whybrow P.C., Andreasen N.C. (1994). Of the muse and moods mundane (editorial). American Journal of Psychiatry, 151, 477-479. 